\title{
Application of thermal imaging system for prediction of fatigue crack initiation in Ti-6Al-4V fabricated by EBM
}

\author{
by P. Koruba*, M. Karoluk*, G. Ziółkowski*, E. Chlebus* \\ *Wroclaw Univ. of Science and Technology, Lukasiewicz Str. 5, 50-371 Wroclaw, Poland, piotr.koruba@pwr.edu.pl
}

\begin{abstract}
Additive manufacturing technology - Electron Beam Melting (EBM) is very promising for providing components with bulk density and high material performance, comparable to wrought material. However fatigue loadings are crucial for application in aerospace and automotive industries. Therefore it is necessary to predict the moment of the crack initiation and find the defect that acts as a stress concentrator within the considered element. The solution described in this paper is passive thermography method conducted during fatigue test of Ti6Al4V specimens as to measure temperature rise during the test. In order to achieve this objective, a thermal imaging system was proposed.
\end{abstract}

\section{Introduction}

Electron Beam Melting (EBM) is one of the powder-bed-fusion additive manufacturing technologies used to fabricate metallic objects. In EBM process metal powder is selectively melted by focused electron beam to form a layer of the object based on CAD data [1,2]. Most commonly applied in EBM material is Ti-6Al-4V, the material with excellent corrosion resistance, low weight ratio and mechanical properties [3]. That promoted applications in aerospace and automotive industries in components which are exposed to cyclic loading [1]. However, in additively manufactured metallic objects, internal defects such as pores, occurred quite common which has negative effect on fatigue properties. To avoid it Hot Isostatic Pressing (HIP) can be applied to close internal defects and improve fatigue properties [4]. Thus, it is necessary to assess fatigue properties in terms of applying additively manufactured components in critical applications.

The use of infrared thermography allows detection of defects, whose presence in case of fatigue loads can lead to a significant reduction in the durability of a given component. According to [5] both active and passive thermography can be used for quality assessment. For example in case of superficial defects in coatings deposited on aerospace components a laser spot thermography may be used [6]. However in case of components subjected to external mechanical loading there is a possibility of passive thermography usage so as to determine their state. In paper [7] authors mentioned that there is a possibility for using thermography in early fatigue of machinery components as well as during laboratory testing. According to [8] the defect inside the fatigue specimen results in local heating due to stress concentration. This fact served as a reason to use passive thermography for determination of damage initiation and its later growth in fabric materials [9] and flat metal specimens [10]. Moreover, Galietti et. al. distinguished three phases of temperature changes during the fatigue testing and determined the fatigue limit using temperature and phase data [5]. The subject of fatigue crack tip propagation was undertaken in paper [11]. However, the authors considered only model situation with preprepared surface crack on the sample.

In this paper the thermal imaging system was developed in order to predict the critical propagation of fatigue crack and initiation of fracture. It was used in case of unidirectional fatigue testing of EBM fabricated Ti6AI4V samples. Subsequently basic crack initiation analysis was performed using industrial computed tomography (CT), which allows three-dimensional reconstruction of the internal and external geometry in a non-destructive manner for thermal imaging system verification.

\section{Experimental setup}

The experiment described below consisted of fatigue testing trials during which a thermal imaging system was used in order to record changes in samples temperature. The aim of this study was to determine the moment of crack initiation and subsequently prepare a method for fatigue test interruption when it occurs. For verification of this experimental method of crack initiation detection a Computer Tomography system was used.

\subsection{Setup for fatigue testing}

For this study, hour-glass shaped specimens according to [12] were fabricated by EBM process using ARCAM A1 machine (Fig. 2 a). All of the samples were built in vertical orientations (Fig. 2 b). For processing Ti-6Al-4V alloy in EBM, ARCAM standard condition was used. After manufacture the specimens were subjected to Hot Isostatic Pressing and then machined to meet ASTM standard. 
a)

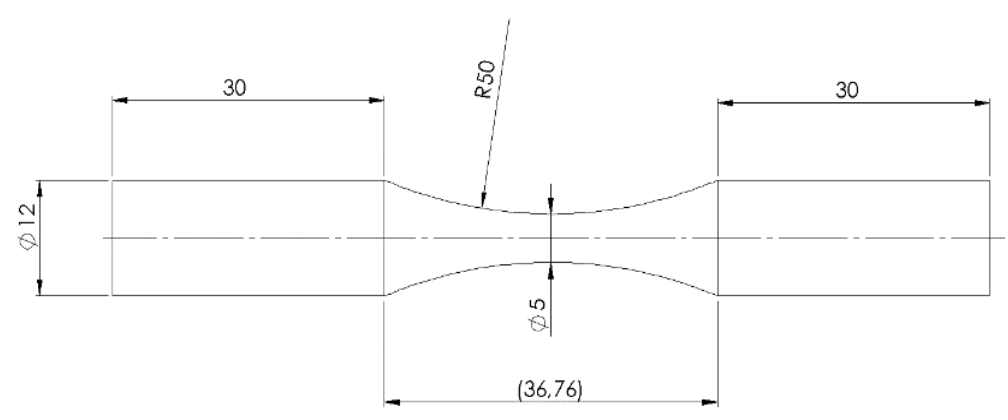

b)

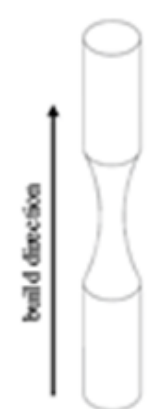

Fig. 1: Fatigue test sample: geometry according to ASTM E466 (a), build direction (b)

The unidirectional tension-tension fatigue tests were carried out with the experimental setup consisted of servo hydraulic testing machine (Instron 8872) with sinusoidal loading test with frequency $50 \mathrm{~Hz}$. The ratio (R) of fatigue test defined as:

$$
R=\frac{\sigma_{\max }}{\sigma_{\min }}
$$

where $\sigma_{\max }$ - maximum stress level and $\sigma_{\min }$ - minimum stress level experienced during the cycle, was established at value 0,1 . Tests were performed at 3 stress levels, where $\sigma_{\max }$ was $700 \mathrm{MPa}, 800 \mathrm{MPa}$ and $900 \mathrm{MPa}$. For each stress level the number of specimens used in the tests was 3 . It is worth underlying that according to ARCAM standard [13] the yield strength of Ti6Al4V alloy obtained in EBM process is about $950 \mathrm{MPa}$.

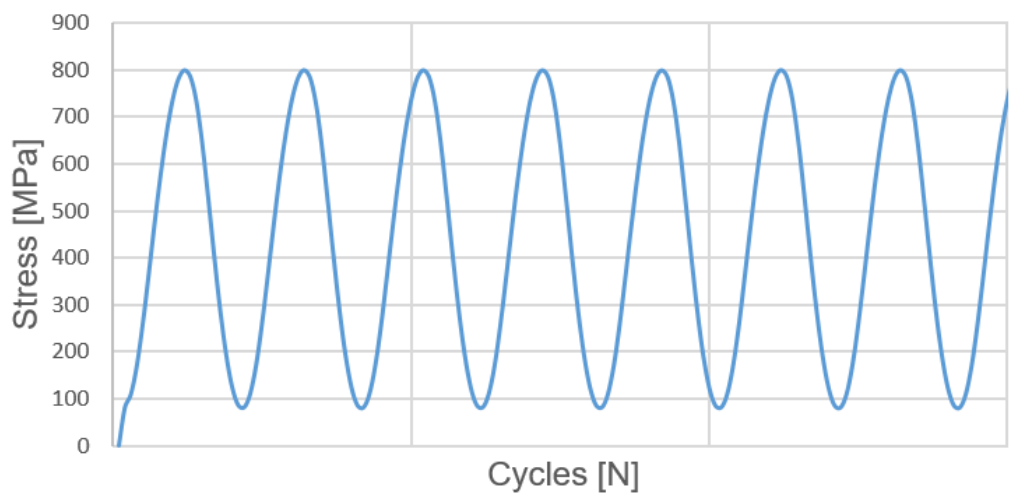

Fig. 2. Exemplary cyclic loading for $\sigma_{\max }-800 \mathrm{MPa}$

\subsection{Description of thermal imaging system}

The thermal imaging system for detection of crack initiation during fatigue testing consisted of thermal camera (FLIR SC7500), acquisition software ResearchIR and microprocessor based ambient temperature measurement system (Fig. 1). The additional temperature sensor DS18B20 was used for detection of ambient temperature changes since fatigue test can be time-consuming. The optics of the camera used for the temperature evaluation was $50 \mathrm{~mm}$ standard lens and the measured temperature range was set to $5^{\circ} \mathrm{C}$ to $70^{\circ} \mathrm{C}$ in camera control. The sampling rate was set to 1 image per second because of the test duration.

In order to obtain reliable measurement of samples temperature during the test all of them were covered with black lacquer with known and constant emissivity. The input parameters for thermal camera as well as main measurement properties of the system were gathered in table 1. It is worth mentioning that based on common approximation:

$$
I F O V_{\text {meas }} \approx 3 \cdot I F O V_{g e o m}
$$

the minimal size of measured object with this thermal imaging system should be about $0.9 \mathrm{~mm}$. Tjis is therefore the system limit for detection of subsurface defect, that may cause cracking initialization. 
a)

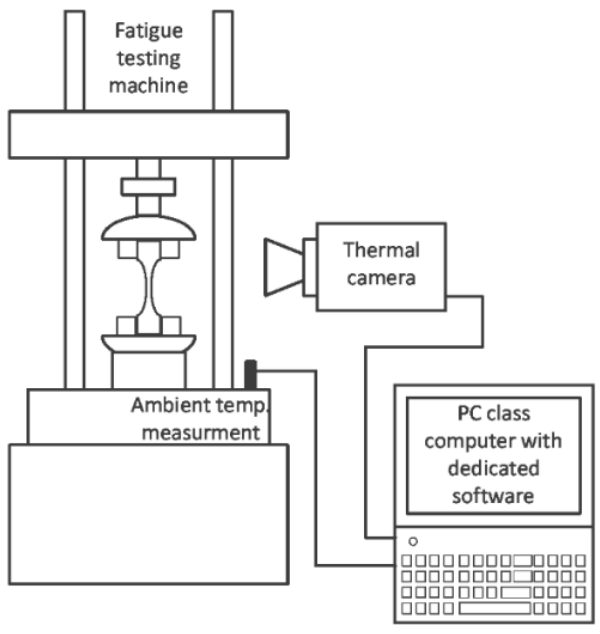

b)

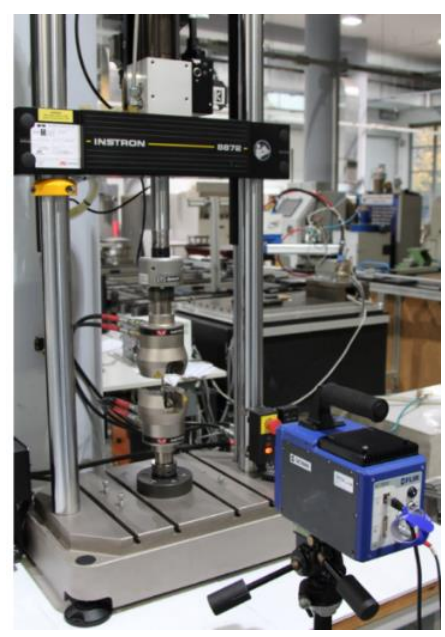

Fig. 3: Experimental site for temperature measurement during fatigue testing: schematics (a), photograph (b)

Table 1. Thermal imaging system configuration parameters

\begin{tabular}{|c|c|c|c|c|c|}
\hline Integration time $(\mathrm{ms})$ & Distance $(\mathrm{m})$ & Emissivity & $\mathrm{T}_{\text {refl }}\left({ }^{\circ} \mathrm{C}\right)$ & $\mathrm{T}_{\text {atm }}\left({ }^{\circ} \mathrm{C}\right)$ & $\mathrm{IFOV}_{\text {geo }}(\mathrm{mm})$ \\
\hline 0.735 & 0.9 & 0.92 & 21.2 & 21,7 & 0.3 \\
\hline
\end{tabular}

\subsection{CT system for verification}

In order to evaluate the developed thermal image system for fatigue testing diagnosis and detection of crack initiation a Computer Tomography was utilized. The sample was placed on a rotating table, between $\mathrm{x}$-ray source and flat panel detector, with the axis precisely adjusted to the center of the fan beam (Fig 4). To obtain a high resolution measurement, the sample was placed near the radiation source and only the area covering its central part was reconstructed. During the measurement, sample was illuminated with a radiation beam and single projections for each angular position of the sample, showing the degree of radiation absorption, were recorded.

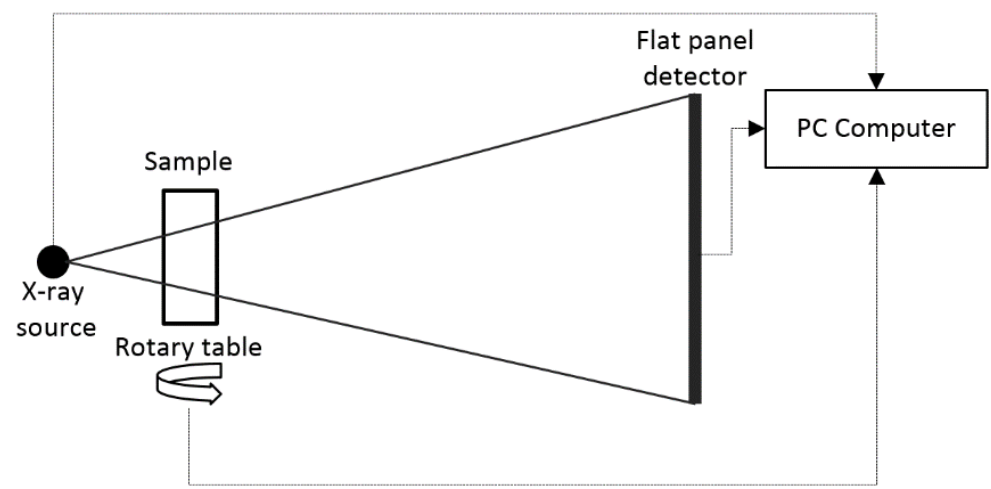

Fig. 4. Schematic illustration of cone beam CT system

The 3D acquisitions and reconstructions were performed using cone beam CT within METROTOM 1500 system. Applied scan parameters and reconstruction were presented in table 2.

Table 2. Scan parameters for CT reconstruction of samples

\begin{tabular}{|c|c|c|c|c|c|}
\hline Voltage $[\mathrm{kV}]$ & Current $[\mu \mathrm{A}]$ & Cu prefilter [mm] & Integration time [s] & Number of views & Voxel size $[\mu \mathrm{m}]$ \\
\hline 200 & 40 & 0,5 & 2 & 600 & 10 \\
\hline
\end{tabular}

For 3D reconstruction Filter Back Projection (FBP) method with Feldkamp algorithm was used. Data visualization and image processing was carried out using the VGStudio MAX 2.0 software. 


\section{Results and discussion}

The discussion of system capabilities that were experimentally tested were divided into section concerning observation of temperature changing until the specimen fracture and the tests with interruption when the crack initiation was observed. In every example of temperature measurement a maximal temperature inside a box region of interest was a parameter for evaluation. It is worth noting that this ROI was placed in the measurement part of the sample.

\subsection{Observation of the cracking}

Although the temperature measurements were conducted for different stress levels, only a representative plot was depicted on figure 5. The sample temperature changes during fatigue testing were shown for $900 \mathrm{MPa}$ stress level. Furthermore the images acquired with thermal camera for particular time moments were depicted. Therefore the temperature chart can be divided into several different parts based on the specimen state. At the begging one can observe fast heating up of the sample and then there is a quasi-steady state with a slight increase in temperature. The most vital part of the plot in case of crack initialisation detection is from point 4 to 6 , where the fracture occurs. In order to prevent the specimen from cracking but successfully acquire information about its initialization, the test should be stopped between points (4) and (5). This part of the plot is characterized by the change of the second derivative sign as the temperature plot becomes a convex function and its first derivative is rising.

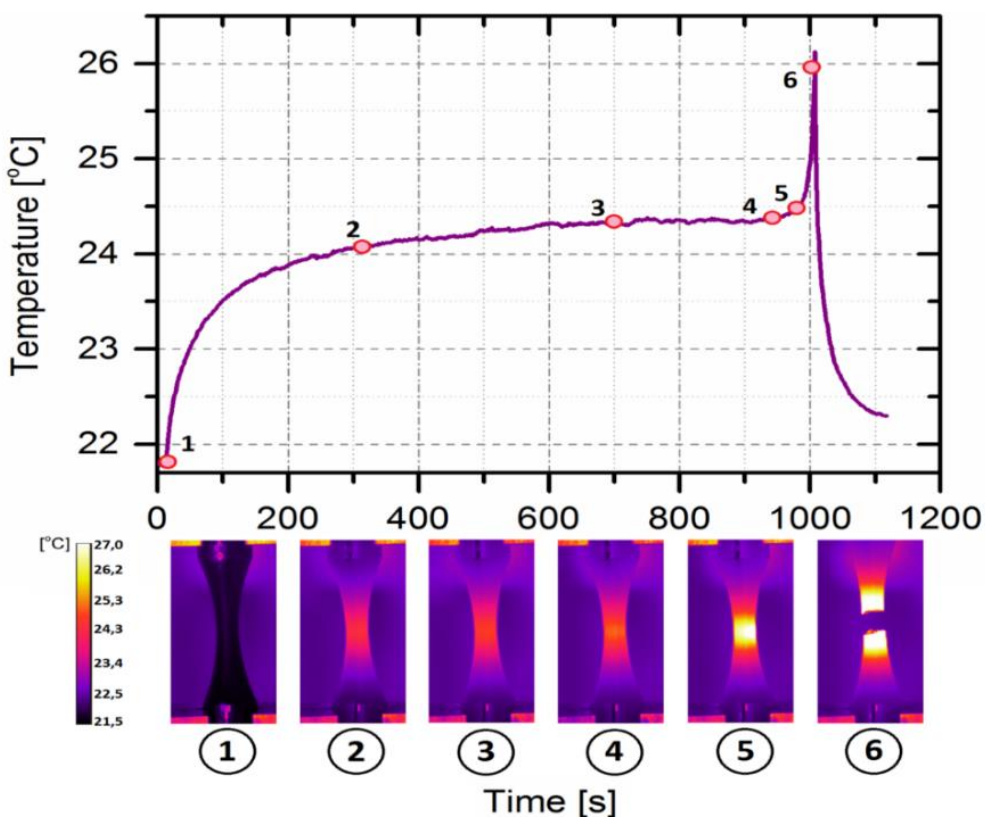

Fig. 5: Temperature of the measuring part of the fatigue sample during the testing with characteristic time steps highlighted: beginning of the test (1), heating-up (2), quasi-steady state (3), subsurface crack initialization (4), subsurface crack propagation (5), fracture of the sample (6)

For more complex analysis the resultative number of cycles $(\mathrm{N})$ and the temperature increase $(\Delta T)$ measured between points 4 and 6 on the temperature plot for each of the considered fatigue sample were gathered in table 3 . It is worth noticing that $\mathrm{N}$ is not a good threshold parameter to stop the fatigue testing. On the other hand, the temperature increase $\Delta T$ is not correlated with the stress level or duration of the fatigue test. It might be related with the energy accumulated inside the defect, so indirectly with the size of subsurface crack.

Table 3. Results of cracking observations for different stress levels

\begin{tabular}{|c|c|c|c|c|}
\hline \multirow{2}{*}{ Measured parameter } & \multirow{2}{*}{ Sample No. } & \multicolumn{3}{|c|}{ Maximum stress level $-\sigma_{\max }$} \\
\cline { 2 - 5 } & & $700 \mathrm{MPa}$ & $800 \mathrm{MPa}$ & $900 \mathrm{MPa}$ \\
\hline \multirow{3}{*}{$\Delta \mathrm{T}\left({ }^{\circ} \mathrm{C}\right)$} & 1 & 9.7 & 24.1 & 7.2 \\
\cline { 2 - 5 } & 2 & 17.1 & 15.6 & 4.5 \\
\cline { 2 - 5 } & 3 & 7.4 & 9.9 & 1.7 \\
\hline \multirow{3}{*}{$\mathrm{N}$ (cycles) } & 1 & 2752422 & 697394 & 219302 \\
\cline { 2 - 5 } & 2 & 4184520 & 1170672 & 387926 \\
\cline { 2 - 5 } & 3 & 1090201 & 1502204 & 50890 \\
\hline
\end{tabular}




\subsection{Verification of the method with CT}

Based on a data discussed above, an exemplary specimen was chosen for fatigue test on 800MPa stress level. The aim of this experiment was to detect the moment, when the crack initialization starts and to interrupt the fatigue test using developed thermal imaging system. In the case of considered sample, the fatigue test was interrupted after 1210047 cycles that was 24201 second from the beginning of the test (Fig. 6). The thermogram shown on Fig. 6a was recorded during interruption of the fatigue test and it shows a heated region on the right side of the specimen axis of symmetry. The temperature increase of the sample was approximately $0.6{ }^{\circ} \mathrm{C}$ and there was no trace of the cracking on the surface.

a)

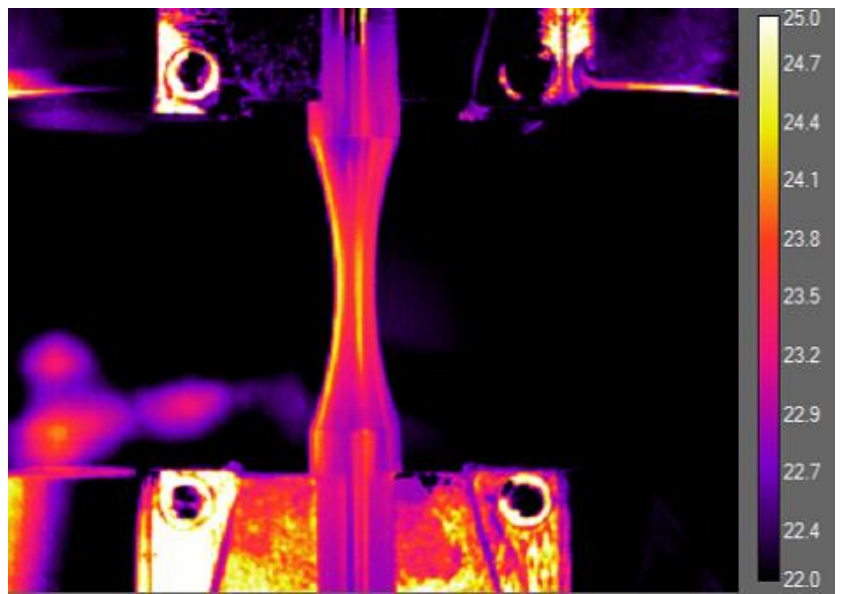

b)

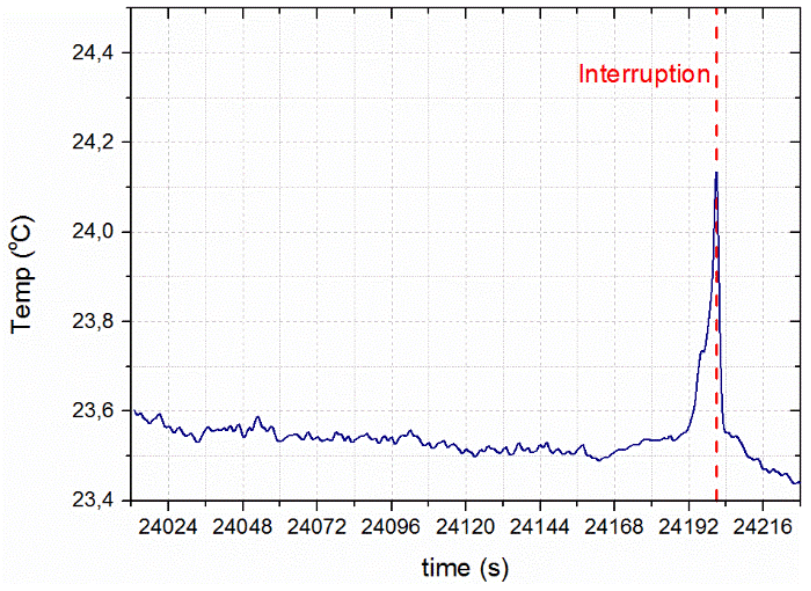

Fig. 6. Data obtained during temperature of fatigue sample: thermal image recorded during test interruption

(a), temperature chart for the time period around the interruption (b)

In order to detect pores or discontinuities that resulted in heating up of the specimen surfaces, the sample was reconstructed before and after fatigue test. Figure 7a shows the result of the sample reconstruction together with the marked plane to which the corresponding cross-sections before and after crack initiation were compared. CT analysis did not reveal the occurrence any pores or discontinuities for the sample before fatigue test, as shown on the basis of a single 2D projection (Fig. 7b), as well as a transparent 3D view for the entire volume of the sample (Fig. 8a). However, subsurface cracks were observed (Figure 7c) for the sample after fatigue test interruption.

a)

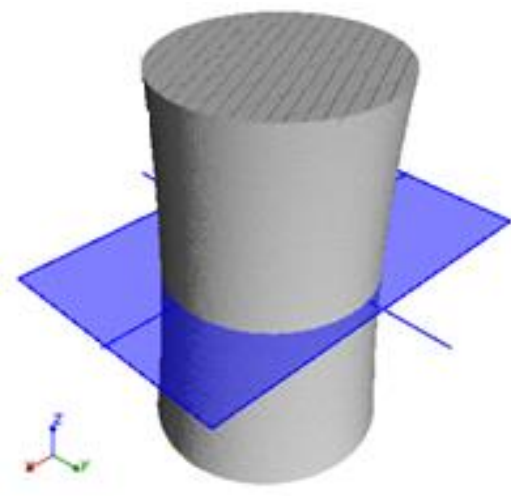

b)

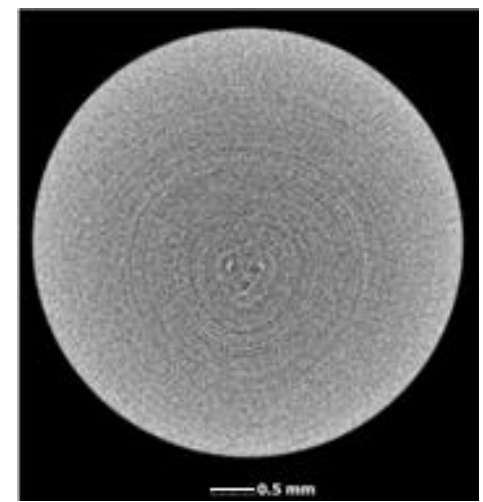

c)

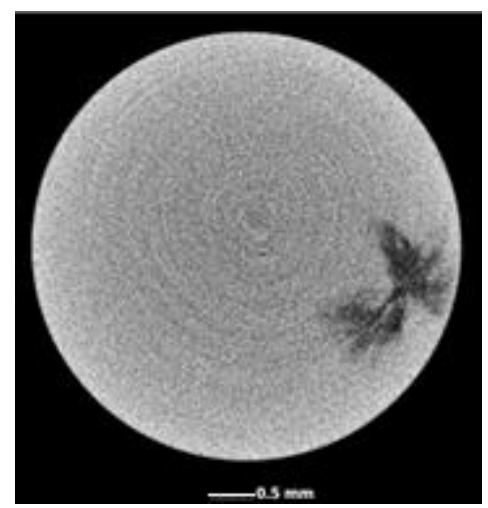

Fig. 7. The result of $C T$ reconstruction: $3 D$ view (a), cross-section before fatigue test (b), cross-section after the crack initiation (c)

Additionally, CT analysis also enabled 3D visualization of fracture geometry that was registered at the time of initialization during cycling test, as shown in figures $8 \mathrm{~b}$ and $8 \mathrm{c}$. 
a)

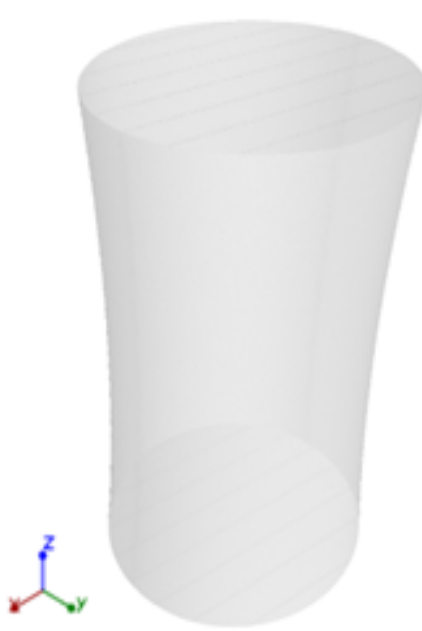

b)

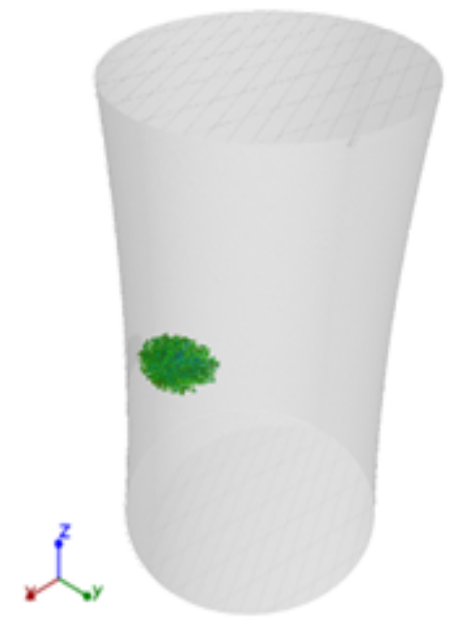

c)

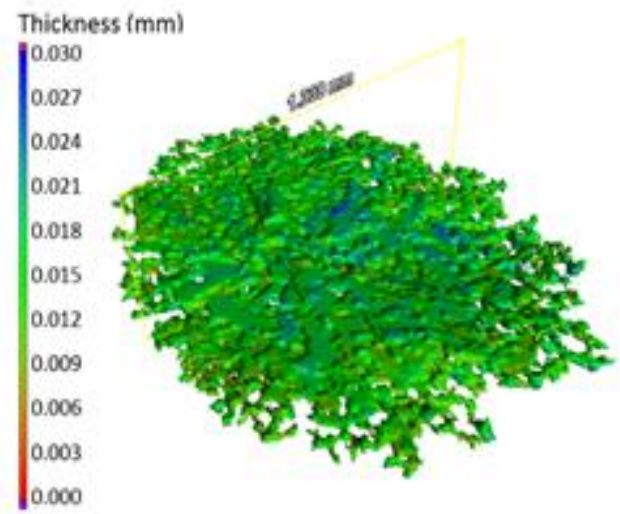

Fig. 8. 3D transparent visualisation: sample scanned before fatigue test (a), sample scanned after the crack initiation (b), crack (fracture) characteristics - dimension and thickness (c)

The measured fracture diameter was at the level $1.338 \mathrm{~mm}$ (volume of $0.033 \mathrm{~mm}^{3}$ ), while the thickness did not exceed $30 \mu \mathrm{m}$. Conducted CT examination indicate the occurrence and development of the fracture (crack) when the temperature of the sample, recorded with the use of a thermal imaging camera, increases.

After performing several short fatigue tests with a number of cycles, the cracking of the sample was recorded by thermal camera. It is remarkable that in this case the maximal temperature during the fracture increased about $68{ }^{\circ} \mathrm{C}$. The reason of this might be controlled growth of the defect that could accumulate more energy. Before the dramatic increase of maximal temperature inside concerned $\mathrm{ROI}$ one can observe sinusoidal change of temperature because of tensiontension cyclic load. This change is noticeable in this case due to increase of frame rate to $25 \mathrm{~Hz}$ and the fact, that the loading frequency was reduced to $1 \mathrm{~Hz}$.

a)

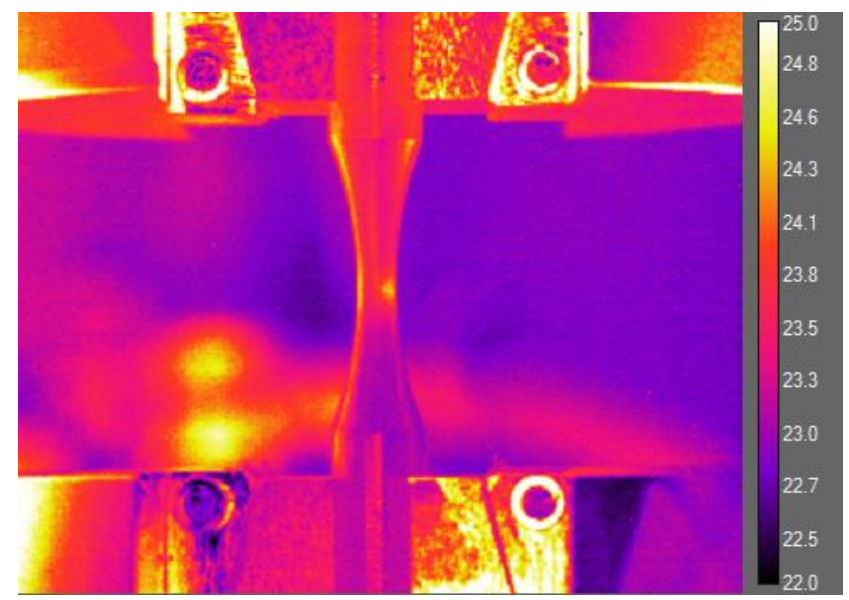

b)

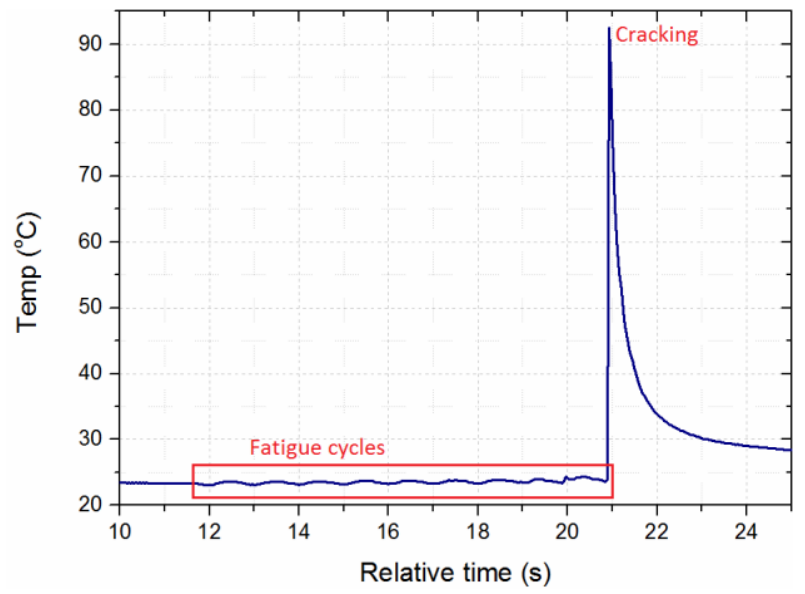

Fig. 9. Data recorded during the cracking of selected fatigue sample: thermogram (a), maximal temperature plot inside measurement part of the sample (b) 


\section{Conclusions}

The applied thermal imaging system allows detection of crack initiation and interruption of the fatigue test being conducted. Moreover the prepared experimental site permits investigating the cracking evolution until fracture by using CT examination. In the presented example, initiation of a crack with a linear size of $1.3 \mathrm{~mm}$ was detected using the developed system, what corresponds with the system accuracy estimated to $0.9 \mathrm{~mm}$.

It was shown that the number of cycles $(\mathrm{N})$ is not a good threshold for interrupting the fatigue test as there is a large variance of this parameter even for the same level of stress. The increase of temperature $(\Delta T)$ is also not a proper quantity to use since it is not repeatable and it might strongly depend on the defect size that cause the cracking. The reliable parameter that can be used for fatigue interruption is therefore the sign of the second derivative of the temperature plot. When the sign becomes positive and the temperature starts to increase rapidly, the test should be stopped.

Moreover, after the interruption and analysis with the CT system, the sample can be subjected to fatigue again in order to determine the evolution of the cracking. It may allow describing the critical size of the defect that cause fracture.

\section{REFERENCES}

[1] Hopkinson N., Hague R., Dickens P., "Rapid manufacturing: an industrial revolution for a digital age", WileyBlackwell, Berlin, 2005.

[2] I. Gibson I., Rosen DW. , Stucker B., "Additive manufacturing technologies: rapid prototyping to direct digital manufacturing" London: Springer; 2010.

[3] Li X., Wang C., Zhang W., Li Y., Fabrication and characterization of porous Ti6Al4V parts for biomedical applications using electron beam melting process, Materials Letters, 2009:63:403-405.

[4] Ackelid U., Svensson M., Additive Manufacturing of Dense Metal Parts by Electron Beam Melting, in: Materials Science and Technology Conference, MS\&T Partner Societies, Pittsburgh, PA, 2009, pp. 2711-2719.

[5] Vollmer M., Möllmann KP, "Infrared Thermal Imaging: Fundamentals, Research and Applications", Wiley VCH Verlag, Weinheim (Germany), 2010

[6] Koruba P., Reiner J., Zakrzewski A., Detection of cracks in laser deposited coatings by laser spot thermography, In: Proceedings of QIRT; 2016; Gdansk, Poland. Available from QIRT Open Archives: http://qirt.gel.ulaval.ca/archives/qirt2016/papers/064.pdf, Paper QIRT 2016-064

[7] Kutin M., Ristić S.,Burzić Z., et al., Testing the Tensile Features of Steel Specimens by Thermography and Conventional Methods, Scientific Technical Review, 2010:60(1):66-70.

[8] Svatner M., Honnerova P., Volak J., Active Thermography in Materials Fatigue Testing, Proceedings of $24^{\text {th }}$ International Conference on Metallurgy and Materials, Brno (Czech Republic), pp. 560-656, 2015.

[9] Banerjee D., Chattopadhyay S. K., Tuli S., Infrared thermography in material research - A review of textile applications, Indian Journal of Fibre \& Textile Research, 2013:38:427-437.

[10] Galietti U., Palumbo D., De Finis R., Ancona F., Fatigue limit evaluation of martensitic steels with thermal methods, In: Proceedings of QIRT; 2014; Bordeaux, France. Available from QIRT Open Archives: http://qirt.gel.ulaval.ca/archives/qirt2014doi/papers/QIRT-2014-105.pdf. Paper QIRT 2014-105.

[11] Iziumova A., Vshivkov A., Plekhov O., The study of the effect of energy dissipation at fatigue crack tip on its propagation rate, In: Proceedings of QIRT; 2016; Gdansk, Poland. Available from QIRT Open Archives: http://qirt.gel.ulaval.ca/archives/qirt2016/papers/101.pdf. Paper QIRT 2016-101

[12] ASTM E466 Standard Practice for Conducting Force Controlled Constant Amplitude Axial Fatigue Tests of Metallic Materials.

[13] Arcam EBM system standard - TI6Al4V Titanium Alloy: http://www.arcam.com/wp-content/uploads/ArcamTi6Al4V-Titanium-Alloy.pdf.

[14] Ziółkowski G, Chlebus E., Szymczyk P., Kurzac J., Application of X-ray CT method for discontinuity and porosity detection in $316 \mathrm{~L}$ stainless steel parts produced with SLM technology, Archives of Civil and Mechanical Engineering, 2014:14(4):608-614.

[15] Feldkamp LA, Davis LC, Kress JW, Practical cone-beam algorithm. J Opt Soc Am 1984:1(A6):612-9 